\title{
Tuning and Locking the Localized Surface Plasmon Resonances of CuS (Covellite) Nanocrystals by an Amorphous $\mathrm{CuPd}_{x} \mathrm{~S}$ Shell
}

Yi Xie, ${ }^{*}, \dagger, \ddagger$ Wenhui Chen, ${ }^{\dagger}$ Giovanni Bertoni, ${ }^{\ddagger}, \S$ Ilka Kriegel, ${ }^{\ddagger}, \|$ Mo Xiong, ${ }^{\dagger}$ Neng Li, ${ }^{\dagger}$ Mirko Prato, Andreas Riedinger, ${ }^{\ddagger} \perp$ Ayyappan Sathya, ${ }^{\ddagger}$ and Liberato Manna*, ${ }^{*}$

${ }^{\dagger}$ State Key Laboratory of Silicate Materials for Architectures, Wuhan University of Technology (WUT), No. 122, Luoshi Road, Wuhan 430070, P. R. China

${ }^{\ddagger}$ Department of Nanochemistry, Istituto Italiano di Tecnologia (IIT), via Morego, 30, 16163 Genova, Italy

${ }^{\S}$ IMEM-CNR, Parco Area delle Scienze 37/A, 43124 Parma, Italy

"Molecular Foundry, Lawrence Berkeley National Laboratory, 1 Cyclotron Road, Berkeley, California 94720, United States

${ }^{\perp}$ Optical Materials Engineering Laboratory, ETH Zurich, 8092 Zurich, Switzerland

\section{Supporting Information}

\begin{abstract}
We demonstrate the stabilization of the localized surface plasmon resonance (LSPR) in a semiconductor-based coreshell heterostructure made of a plasmonic $\mathrm{CuS}$ core embedded in an amorphous-like alloyed $\mathrm{CuPd}_{x} \mathrm{~S}$ shell. This heterostructure is prepared by reacting the as-synthesized $\mathrm{CuS}$ nanocrystals (NCs) with $\mathrm{Pd}^{2+}$ cations at room temperature in the presence of an electron donor (ascorbic acid). The reaction starts from the surface of the CuS NCs and proceeds toward the center, causing reorganization of the initial lattice and amorphization of the covellite structure. According to density functional calculations, $\mathrm{Pd}$ atoms are preferentially accommodated between the bilayer formed by the $S-S$ covalent bonds, which are therefore broken, and this can be understood as the first step leading to amorphization of the particles upon insertion of the

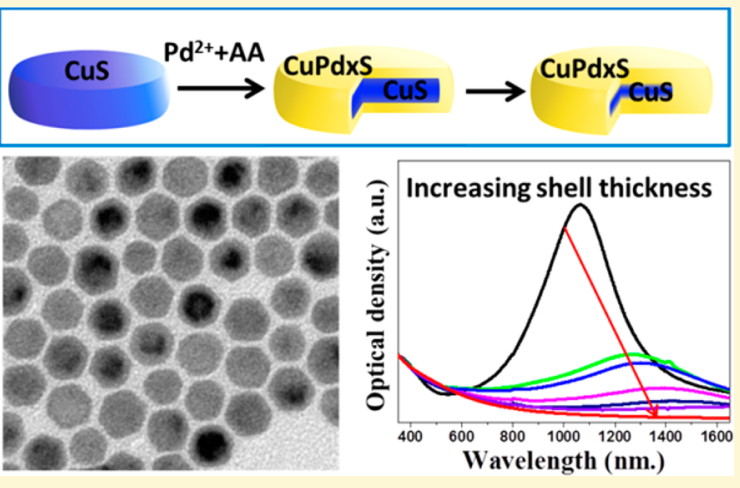
$\mathrm{Pd}^{2+}$ ions. The position and intensity in near-infrared LSPRs can be tuned by altering the thickness of the shell and are in agreement with the theoretical optical simulation based on the Mie-Gans theory and Drude model. Compared to the starting $\mathrm{CuS} \mathrm{NCs,} \mathrm{the} \mathrm{amorphous} \mathrm{CuPd}_{x} \mathrm{~S}$ shell in the core-shell nanoparticles makes their plasmonic response less sensitive to a harsh oxidation environment (generated, for example, by the presence of $\mathrm{I}_{2}$ ).
\end{abstract}

\section{INTRODUCTION}

The emergence of localized surface plasmon resonances (LSPRs), not only in nanosized metals but also in semiconductors, has attracted significant attention in the past several decades. $^{1-20}$ The plasmon modes arise from the collective and coherent oscillations of the free carriers (i.e., electrons or holes) in resonance with the incident light frequency on the surface of metal or semiconductor nanoparticles (NPs). The plasmon absorbance of NPs can be located in various regions of the spectrum, depending on the particle composition, size, shape, and surface functionalization. ${ }^{21-23}$ Plasmon resonances of metallic NPs have already found a multitude of applications in fields ranging from surface-enhanced Raman spectroscopy, photothermal therapy for biomedicine, imaging, and catalysis. ${ }^{1-4}$ Colloidal semiconductor nanocrystals (NCs) of binary copper chalcogenides $\left(\mathrm{Cu}_{2-x} \mathrm{E}\right.$, where $\mathrm{E}=\mathrm{S}$, Se, or $\left.\mathrm{Te}\right)$ have also emerged as a new set of plasmonic materials, because of their unique and tunable LSPRs in the near-infrared (NIR) region, ${ }^{5-19}$ which makes them suitable for various applications, as well. ${ }^{24-36}$ The interest in these materials started when Zhao et al. attributed the NIR optical absorbance band of $\mathrm{Cu}_{2-x} \mathrm{~S}$
NCs to a plasmon resonance effect ${ }^{15}$ and then when Luther et al. investigated in more detail the plasmonic properties of $\mathrm{Cu}_{2-x} \mathrm{~S}$ NCs. ${ }^{5}$ In $\mathrm{Cu}_{2-x} \mathrm{E} \mathrm{NCs}$, the density of free carriers, hence the spectral position of the NIR plasmon resonance, depends on the density of $\mathrm{Cu}$ vacancies (i.e., $x$ ), which in turn can be strongly influenced by the surrounding environment. For instance, by exposure of the NCs to oxidizing agents such as air, iodine, or a $\mathrm{Ce}(\mathrm{IV})$ complex $^{15,19,37}$ or to reducing agents such as diisobutylaluminum hydride (DIBAH), ${ }^{7}$ their $\mathrm{Cu}$ stoichiometry can be altered. This is currently understood to proceed through the concomitant extraction of electrons and $\mathrm{Cu}^{+}$ions in an oxidizing environment or the opposite process in a reducing environment, each involving a change in the plasmonic response. Despite the very recent success in stabilization of NIR LSPRs of $\mathrm{Cu}_{2-x} \mathrm{~S}$ NCs with a surface layer of tetrathiomolybdate $\left(\mathrm{MoS}_{4}{ }^{2-}\right)$ by ligand exchange, ${ }^{38}$ the

Received: December 7, 2016

Revised: January 26, 2017

Published: January 26, 2017 
precise control over plasmon properties remains an important issue.

Covellite $(\mathrm{CuS})$ NCs make up another class of plasmonic materials that have recently come under scrutiny. Here, the metallic behavior of bulk covellite and the LSPR in NCs is not due to the presence of $\mathrm{Cu}$ vacancies but arises from the peculiar electronic structure of the material. ${ }^{9}$ On one hand, covellite NCs therefore raise problems similar to those of the $\mathrm{Cu}_{2-x} \mathrm{E}$ NCs. On the other hand, they exhibit a reactivity completely different from that of $\mathrm{Cu}_{2-x} \mathrm{E}$ NCs when they are exposed to a reducing environment in the presence of metal cations, as reported in a previous paper of ours. ${ }^{40}$ Most notably, they can incorporate various metal cations, without releasing $\mathrm{Cu}^{+}$ions in exchange, a feature that can be used for the recovery of heavy metals.

As a noble metal, Pd occurs in ores in nature and can be associated with mineral covellite deposits, but no known compounds with a ternary $\mathrm{Cu}-\mathrm{Pd}-\mathrm{S}$ composition have been reported to date. ${ }^{41}$ In the work presented here, we show that, by reaction of covellite $\mathrm{NCs}$ with $\mathrm{Pd}^{2+}$ ions in a reducing environment in solution, $\mathrm{Pd}$ is slowly incorporated into the particles, transforming their outer regions into an amorphous $\mathrm{CuPd}_{x} \mathrm{~S}$ shell that grows in thickness depending on various parameters (reaction time, amount of $\mathrm{Pd}$ precursor, and temperature), until all the NCs are amorphized. The intermediate core-shell NCs preserve a covellite core, and their overall NIR absorbance can be spectrally tuned depending on the thickness of the amorphous shell. Most importantly, their plasmonic response becomes relatively insensitive to the external redox environment, and the resulting NCs are much more stable than the initial covellite NCs, especially under strongly oxidizing conditions, for example, when they are exposed to agents such as $\mathrm{I}_{2}$. These observations are appealing not only for noble metal recovery but also for the fabrication of semiconductor-based core-shell heterostructure with tunable and stable plasmon properties.

\section{EXPERIMENTAL SECTION}

Materials. Copper chloride (CuCl, anhydrous, 99.99\%), palladium(II) acetylacetonate $\left[\mathrm{Pd}(\mathrm{ac})_{2}, 99 \%\right]$, ascorbic acid (AA), oleylamine (OM, >70\%), and octadecene (ODE, 90\%) were purchased from Sigma-Aldrich. Elemental sulfur (99\%) was from Strem Chemicals, and ethanol (anhydrous, 99.9\%), methanol (anhydrous, 99.9\%), and toluene (anhydrous, 99.8\%) were from Carlo Erba reagents. All chemicals were used as received without further purification.

Synthesis of Covellite Nanocrystals. Covellite $\mathrm{CuS}$ nanoplates were synthesized according to a modified protocol reported previously by us. ${ }^{42}$ Briefly, a sulfur solution was prepared first by degassing a mixture of $0.160 \mathrm{~g}(5 \mathrm{mmol})$ of sulfur, $25 \mathrm{~mL}$ of ODE, and $25 \mathrm{~mL}$ of $\mathrm{OM}$ in a $100 \mathrm{~mL}$ three-neck flask at $130{ }^{\circ} \mathrm{C}$ under vacuum for $30 \mathrm{~min}$. The as-formed clear yellow solution was cooled to room temperature (RT) under a $\mathrm{N}_{2}$ atmosphere, followed by addition of $0.248 \mathrm{~g}(2.5$ $\mathrm{mmol}$ ) of $\mathrm{CuCl}$ and degassing at $\mathrm{RT}$ for an additional $60 \mathrm{~min}$. The asobtained dark green solution was then heated to $200{ }^{\circ} \mathrm{C}$ with a ramp of $8{ }^{\circ} \mathrm{C} / \mathrm{min}$, and the reaction mixture was kept at this temperature for $30 \mathrm{~min}$. A resulting dark green solution was collected after the mixture had been cooled to RT, cleaned twice with a methanol/acetone [1:1 (v:v)] mixture, and finally dispersed in toluene for further characterization and reaction.

Synthesis of CuS@CuPd $\mathrm{S}_{x}$ Core-Shell Heterostructure. The $\mathrm{CuS@CuPd} \mathrm{S}_{x}$ core-shell NCs were prepared by reacting covellite $\mathrm{CuS}$ NCs with $\mathrm{Pd}^{2+}$ cations in the presence of AA. The reactions were performed in a $\mathrm{N}_{2}$-filled glovebox. Typically, $\mathrm{Pd}^{2+}$ (in toluene) and $\mathrm{AA}$ (in methanol) solutions were prepared by dissolving $\mathrm{Pd}(\mathrm{ac})_{2}$ in toluene at around $45{ }^{\circ} \mathrm{C}$ for $30 \mathrm{~min}$ and $\mathrm{AA}$ in methanol at $\mathrm{RT}$, respectively. The concentrations of $\mathrm{Pd}^{2+}$ and $\mathrm{AA}$ solutions were 0.02 and $0.1 \mathrm{M}$, respectively. Then, $0.05 \mathrm{~mL}$ of $\mathrm{OM}, 1.65 \mathrm{~mL}$ of $\mathrm{AA}$, and $1.65 \mathrm{~mL}$ of $\mathrm{Pd}^{2+}$ solutions were added to a vial with $3.0 \mathrm{~mL}$ of the covellite $\mathrm{NC}$ dispersion $\left(0.033 \mathrm{mmol}\right.$ of $\mathrm{Cu}^{+}$cations, in toluene) while being magnetically stirred. Aliquots of the $\mathrm{NC}$ solution $(1.0 \mathrm{~mL})$ were collected at different reaction times to monitor the evolution of morphologies, optical spectra, compositions, and other features. The aliquots, as well as the final sample collected after reaction for $24 \mathrm{~h}$, were precipitated by addition of $0.5 \mathrm{~mL}$ of methanol and centrifugation at $3000 \mathrm{rpm}$ for $20 \mathrm{~min}$. The supernatant was then carefully collected for elemental analysis (see below), and the precipitates were dispersed in toluene for one additional cleaning cycle. The final precipitate was redispersed in toluene $(0.5 \mathrm{~mL})$ for subsequent characterization, including elemental analysis.

Oxidation/Reduction Experiments. To test the stability of the as-synthesized covellite $\mathrm{NCs}$ and the $\mathrm{CuS} @ \mathrm{CuPd}_{x} \mathrm{~S}$ core-shell nanostructure upon oxidation, we monitored the evolution of the optical spectra by exposing the samples to air or an $\mathrm{I}_{2}$ solution. The oxidation experiments with $\mathrm{I}_{2}$ were performed in a $\mathrm{N}_{2}$-filled glovebox, and the optical spectra were tracked with dose of $\mathrm{I}_{2}$. Typically, different portions of an $\mathrm{I}_{2}$ solution $(0.05 \mathrm{M}$, in toluene) were added to a cuvette containing $3 \mathrm{~mL}$ of a colloidal NC solution. The cuvette was then sealed, and the mixed solution was taken out of the glovebox to record the optical spectra $5 \mathrm{~min}$ after the addition of $\mathrm{I}_{2}$. The stability of the various samples upon reduction was also monitored in the glovebox, following a similar procedure of the oxidation by $\mathrm{I}_{2}$ except that diisobutylaluminum hydride (DIBAH) was now introduced. Different volumes of a DIBAH solution ( $0.05 \mathrm{M}$, in toluene) were added to a cuvette containing $3 \mathrm{~mL}$ of a NC solution. The mixed solution was then taken out of the glovebox for optical characterization. In the typical morphological and structural characterizations of the oxidized and reduced NCs, $1 \mathrm{~mL}$ of $\mathrm{I}_{2}(0.05 \mathrm{M}$, in toluene) or a DIBAH solution $(0.05 \mathrm{M}$, in toluene) was added to a dispersion of $\mathrm{CuS}$ or CuS@CuPd $\mathrm{S}$ NCs while being stirred at RT. The I:S and DIBAH:S molar ratios were both fixed to $3: 1$. The precipitate was collected after addition of $2 \mathrm{~mL}$ of ethanol and centrifugation and was redispersed in toluene. Drops of the resulting nanoparticle solution were deposited on carbon-coated grids for transmission electron microscopy (TEM) analysis or on a $\mathrm{Si}$ substrate for X-ray diffraction measurements.

Transmission Electron Microscopy (TEM). Low-resolution TEM measurements were taken on a JEOL JEM-1011 microscope operating at an acceleration voltage of $100 \mathrm{kV}$. The samples were prepared by drop-casting NC solutions on carbon-coated 200 mesh copper grids. High-resolution TEM (HRTEM) analysis was performed with a JEOL JEM-2200FS microscope equipped with a field emission gun working at $200 \mathrm{kV}$, a CEOS spherical aberration corrector in the objective lens allowing for a spatial resolution of $0.9 \AA$, and an incolumn $\Omega$ energy filter. Image simulation was performed with xHREM software (HREM Research, Inc.). The chemical composition of the NCs was determined by energy dispersive X-ray spectroscopy (EDS) performed in large-angle annular dark field scanning TEM (HAADFSTEM) mode on a Bruker Quantax 400 system with a $60 \mathrm{~mm}$ XFlash 6T silicon drift detector, using the Cliff-Lorimer method. For HRTEM and STEM-EDS analyses, the samples were prepared by drop-casting NC solutions onto ultrathin carbon-coated 300 mesh gold grids, which were then placed in a high-vacuum pumping station to let the solvent evaporate completely and preserve the NCs from oxidation.

X-ray Diffraction (XRD). XRD measurements were performed on a Rigaku SmartLab X-ray diffractometer operating at $40 \mathrm{kV}$ and 150 $\mathrm{mA}$. The diffractometer was equipped with a $\mathrm{Cu}$ source and a Göbel mirror to have a parallel beam, and it was used in $2 \theta / \omega$ scan geometry for the acquisition of the data. The specimens were prepared in a $\mathrm{N}_{2}-$ filled glovebox by drop-casting the concentrated NC solution onto a zero-background silicon substrate followed by drying. PDXL software of Rigaku was used for phase identification.

Elemental Analysis. Inductively coupled plasma optical emission spectroscopy (ICP-OES) was performed on an iCAP 6000 spectrometer (ThermoScientific) for quantification of the elemental composition of NC samples and of the supernatant solutions. The 
samples were decomposed in aqua regia $\left[3: 1\right.$ (v:v) $\left.\mathrm{HCl}: \mathrm{HNO}_{3}\right]$ overnight prior to ICP-OES measurements.

X-ray Photoelectron Spectroscopy (XPS). The samples were prepared in a $\mathrm{N}_{2}$-filled glovebox by drop-casting a few microliters of NC solutions onto a graphite substrate (HOPG, ZYB quality, NTMDT) and then transferred to the XPS setup in an ad hoc transfer vessel to prevent air exposure. Measurements were taken on a Kratos Axis Ultra DLD spectrometer, using a monochromatic $\mathrm{Al} \mathrm{K \alpha}$ source $(15 \mathrm{kV}, 20 \mathrm{~mA})$. Wide scans were acquired at an analyzer pass energy of $160 \mathrm{eV}$. High-resolution narrow scans were performed at a constant pass energy of $10 \mathrm{eV}$ in $0.1 \mathrm{eV}$ steps. Photoelectrons were detected at a takeoff angle $\Phi$ of $0^{\circ}$ with respect to the surface normal. The pressure in the analysis chamber was maintained below $7 \times 10^{-9}$ Torr for data acquisition. Data were converted to VAMAS format and processed using CasaXPS version 2.3.16. The binding energy scale was internally referenced to the $\mathrm{C} 1 \mathrm{~s}$ peak ( $\mathrm{BE}$ for $\mathrm{C}-\mathrm{C}$ of $285 \mathrm{eV}$ ).

Optical Spectroscopy. Raman spectra were recorded on a Jobin Yvon HR800 spectrometer. The NCs were deposited on silicon substrates under $\mathrm{N}_{2}$. Data were acquired at a $\lambda$ of $632.8 \mathrm{~nm}$ with a $50 \times$ objective using a nominal power of $25 \mathrm{~mW}$ and an integration time of 30 s. UV-Vis-NIR extinction spectra of the NC solutions were recorded on a Varian Cary 5000 UV-Vis-NIR spectrophotometer in the range of $350-2000 \mathrm{~nm}$.

\section{RESULTS AND DISCUSSION}

In an initial series of experiments, the CuS NCs were mixed with $\mathrm{Pd}^{2+}$ ions alone (with no addition of $\mathrm{AA}$ ). This produced a damping and red-shift of their NIR surface plasmon absorbance, most likely because of the surface passivation by $\mathrm{Pd}$ species, but no significant incorporation of $\mathrm{Pd}$ in the NCs was recorded, as the Pd:Cu molar ratio in the resulting sample, after cleaning, was only around 0.05:1 (determined by ICP analysis). Also, no noticeable change in the diffraction pattern or in the morphology of the particles was observed (see Figure $\mathrm{S} 1)$. When instead the $\mathrm{CuS}$ NCs were mixed with both $\mathrm{Pd}^{2+}$ ions and AA, their NIR LSPRs experienced a much more pronounced red-shift and damping (this aspect will be elucidated in depth below). Such behavior bears analogy with our previously reported reaction of covellite NCs with $\mathrm{Cd}^{2+}$ and $\mathrm{Hg}^{2+}$ in the presence of AA. ${ }^{40}$ Here, while there was no noticeable change in the overall morphology or size of the particles (Figures S2a-g and S3), the differences in contrast within many individual NCs, as seen by conventional TEM analysis (for example, Figure $1 \mathrm{~b}$ and Figure $\mathrm{S} 2 \mathrm{~b}-\mathrm{g}$ ), pointed to a core-shell structure.

According to XRD analysis, there was a progressive loss of crystallinity of the NCs, as the initial covellite pattern evolved to one characterized by only broad features (ranging from $24^{\circ}$ to $40^{\circ}$ ) that could not be assigned to $\mathrm{PdS}$ or to $\mathrm{Cu}_{2-x} \mathrm{~S}$ phases (Figure $1 \mathrm{~d}$ and Figure S2h). Instead, the broad XRD feature in the range of $20-50^{\circ}$ was also observed by Wang et al. in their recently reported amorphous $\mathrm{Cu}-\mathrm{Pd}-\mathrm{S}$ nanostructure obtained by reacting $\mathrm{CuS} \mathrm{NCs}$ with $\mathrm{Pd}$ species at $150{ }^{\circ} \mathrm{C}$ (a temperature much higher than RT used in our reactions). ${ }^{43}$ We can therefore speculate that this feature arises from the quasiamorphous $\mathrm{Cu}-\mathrm{Pd}$ sulfide regions. The change in the relative intensities of the various peaks might indicate different amorphization speeds along different directions. For example, one can see from Figure $1 \mathrm{~d}$ that, at $4 \mathrm{~h}$ of reaction, the relative intensity of the diffraction peak at $31.8^{\circ}$ [indexed to the (103) planes] has decayed faster than that of the peak at $47.9^{\circ}$ [indexed to the (110) planes] (see the details in the Supporting Information). On the other hand, we cannot rule out the possibility that some XRD peaks are more intense than others because of preferential orientation effects.
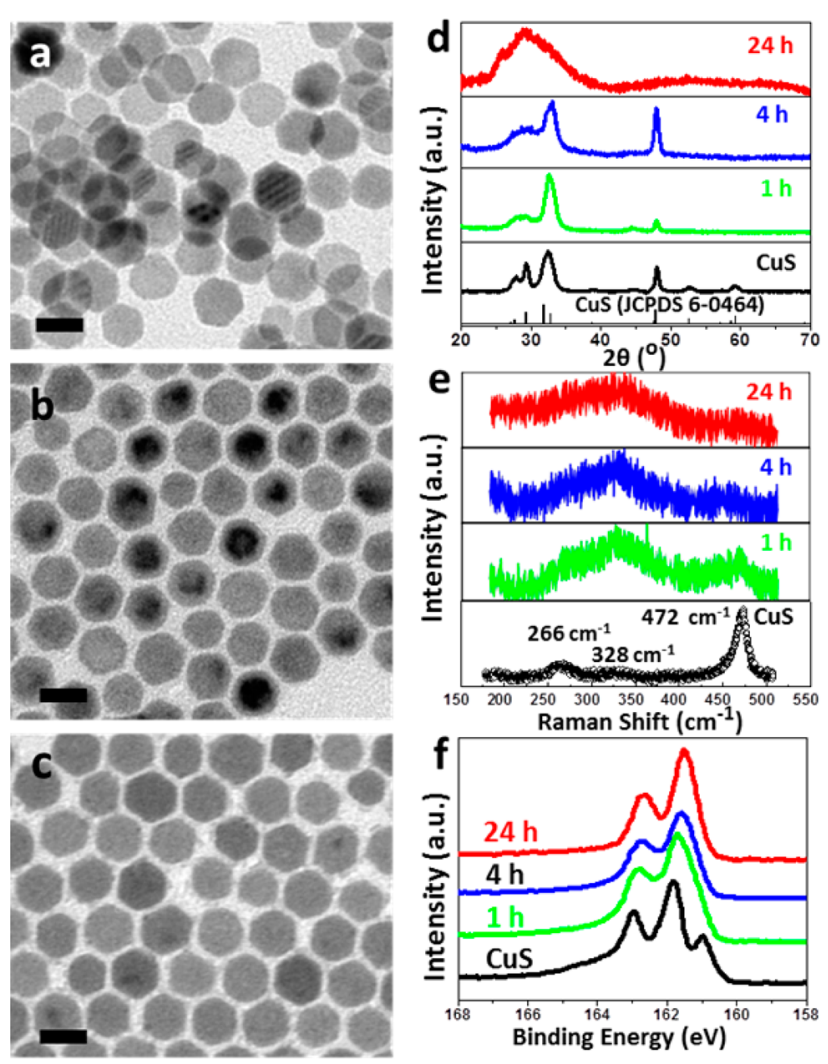

Figure 1. Representative TEM images of the (a) as-synthesized covellite NCs and (b and c) $\mathrm{CuS} @ \mathrm{CuPd}_{x} \mathrm{~S}$ core-shell nanostructure collected at 4 and $24 \mathrm{~h}$, respectively, by reacting covellite NCs with $\mathrm{Pd}^{2+}$ cations at RT in the presence of AA. The scale bar is $20 \mathrm{~nm}$. (d) Evolution of the experimental XRD patterns, (e) Raman spectra, and (f) high-resolution XPS spectra of the $S 2 p$ region from the assynthesized CuS NCs and from representative core-shell nanostructures collected at different reaction times.

We investigated the evolution of Raman spectra and XPS spectra in the $\mathrm{Cu} 2 \mathrm{p}, \mathrm{Pd} 3 \mathrm{~d}$, and $\mathrm{S} 2 \mathrm{p}$ regions, for the most representative samples, namely, the initial covellite NCs and samples collected at various times after the start of the reaction (see Figure 1e,f, Figure S4a-c, and Figure S5). As the incorporation of $\mathrm{Pd}^{2+}$ in $\mathrm{CuS}$ in the presence of $\mathrm{AA}$ proceeded, the main Raman mode at around $472 \mathrm{~cm}^{-1}$, which is ascribed to the covalent $\mathrm{S}-\mathrm{S}$ stretching vibration $\left(\mathrm{A}_{1 \mathrm{~g}}\right.$ mode) of the two tetrahedral $\mathrm{CuS}_{4}$ units in covellite $\mathrm{CuS},{ }^{44}$ broadened and redshifted (to around $450 \mathrm{~cm}^{-1}$ ), and its intensity decreased, signifying the breaking of an increasing fraction of $S-S$ bonds. The $S-S A_{1 g}$ mode faded almost completely after reaction for $24 \mathrm{~h}$, indicating almost no $\mathrm{S}-\mathrm{S}$ bonds in the final NCs. Here, as in our previously reported reaction of covellite $\mathrm{NCs}$ with $\mathrm{Cd}^{2+}$ and $\mathrm{Hg}^{2+}$ ions, the broad feature at $220-400 \mathrm{~cm}^{-1}$ in the Raman spectra was probably due to the overlapping vibrational modes of $\mathrm{Cu}-\mathrm{S}$ and $\mathrm{Pd}-\mathrm{S}$ bonds and a contribution from a $\mathrm{Si}-\mathrm{Si}$ vibrational mode from the substrate (Figure 1e). ${ }^{40}$ If these samples were annealed at $100{ }^{\circ} \mathrm{C}$ under a $\mathrm{N}_{2}$ atmosphere for $1 \mathrm{~h}$, their Raman spectra evidenced new peaks at 323, 346, and $386 \mathrm{~cm}^{-1}$ (Figure $\mathrm{S} 4 \mathrm{~d}-\mathrm{f}$ ), which are due to $\mathrm{Pd}-\mathrm{S}$ vibrational modes. 45,46

Progressive breaking of the $S-S$ bonds of the initial covellite lattice was also proven by high-resolution XPS analysis (Figure If and Figure S5). The evolution of characteristic peaks observed in the $S 2 \mathrm{p}$ region, which permits the discrimination 
between sulfides and disulfides ( $\mathrm{S}-\mathrm{S}$ covalent bonds), indeed, confirmed the gradual fading of the $\mathrm{S}-\mathrm{S}$ signal as the shell grew progressively thicker. Therefore, as the vast majority of $S-S$ bonds in the starting $\mathrm{CuS} \mathrm{NCs}$ were broken in the reacted NCs, we expect a significant reorganization of the initial crystal lattices. This reorganization of the lattice framework led to the release of a fraction of $\mathrm{Cu}$ and $\mathrm{S}$ species from the initial $\mathrm{CuS}$ NCs to the solution phase, as found by ICP elemental analysis of the supernatant (after reaction and centrifugation) and EDS analysis on the resulting core-shell NCs. However, this loss was never greater than $\sim 10 \%$ of the total amount of $\mathrm{Cu}$ and $\mathrm{S}$ of the starting NCs.

The core-shell structure of the intermediate samples collected within $24 \mathrm{~h}$ (i.e., before the incorporation of $\mathrm{Pd}^{2+}$ ions was extended to the whole NCs) was evident from HRTEM analysis (Figure 2). Indeed, we noticed that an
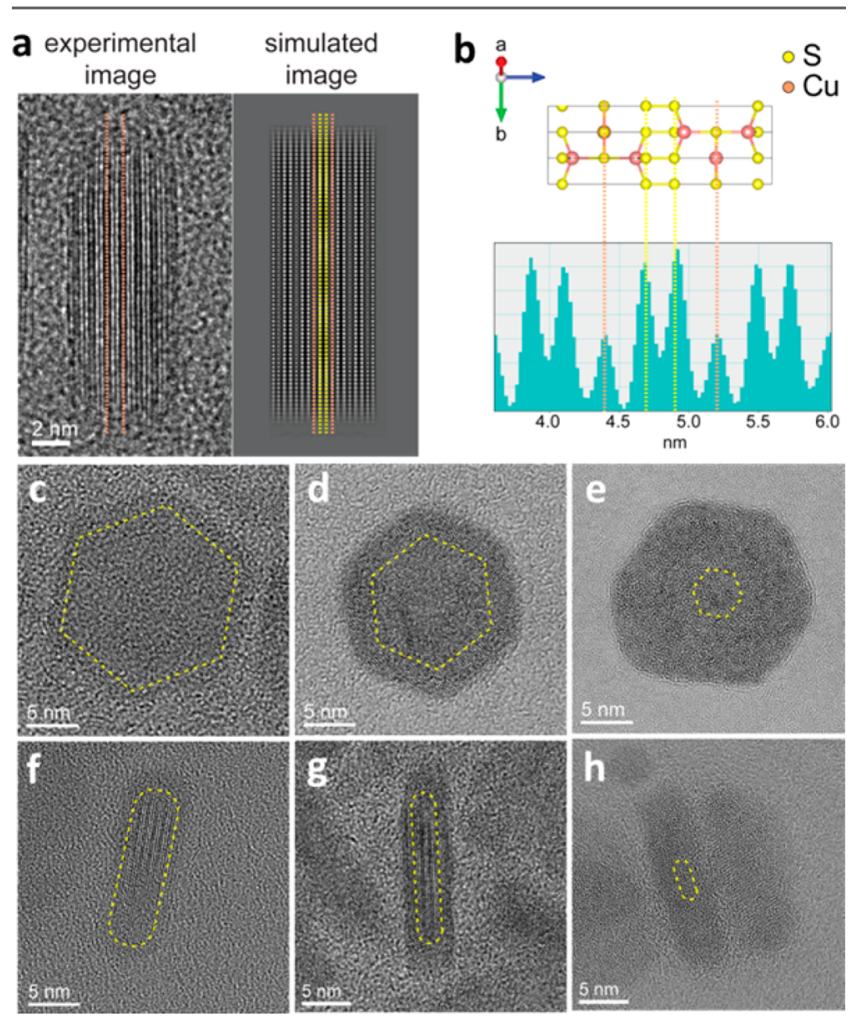

$\mathrm{nm}$

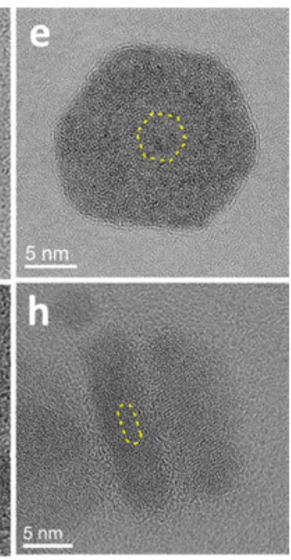

Figure 2. (a) Experimental image (defocus $-34 \mathrm{~nm}$, spherical aberration $-26 \mathrm{~nm}$ ) and simulated image from a [210] side view of a covellite NC. At this defocus value, the intensity is transferred to the $S-S$ planes (yellow dotted lines), as seen in the intensity profile (b). This feature was used to determine the covellite core size reduction during exposure to $\mathrm{Pd}^{2+}$ ions. $(\mathrm{c}-\mathrm{e})$ Top-view and $(\mathrm{f}-\mathrm{h})$ side-view HRTEM images of the CuS@ $\mathrm{CuPd}_{x} \mathrm{~S}$ core-shell heterostructures with different shell thicknesses, at $1 \mathrm{~h} \mathrm{(c} \mathrm{and} \mathrm{f),} 4 \mathrm{~h}$ ( $\mathrm{d}$ and $\mathrm{g}$ ), and $24 \mathrm{~h}$ ( $\mathrm{e}$ and $\mathrm{h}$ ) of reaction of $\mathrm{CuS}$ with $\mathrm{Pd}^{2+}$ ions at $\mathrm{RT}$, in the presence of AA. The yellow dashed lines mark approximately the covellite core.

appropriate choice of the defocus value makes the $S-S$ layers of covellite appear bright in the image from the side view (Figure $2 \mathrm{a}, \mathrm{b})$, which has been used to identify a reduction in size or damage of the covellite core upon reaction with $\mathrm{Pd}^{2+}$. The analysis revealed an amorphous structure of the shell and crystalline core still maintaining the covellite structure, i.e., the inner region of the NCs that most likely had not yet been reached by the Pd species. The core undergoes a reduction in size as seen either in top-view images from nanodisks lying flat on the carbon support film (Figure $2 \mathrm{c}-\mathrm{e}$ ) or in side-view images from disks lying edge-on with respect to the substrate (Figure $2 \mathrm{f}-\mathrm{h}$ ). Additional HRTEM images in false colors are displayed in Figure S6.

To understand the parameters that influence the reaction, we also tailored the precursor $\mathrm{Pd}: \mathrm{Cu}$ molar ratios and the reaction temperature to monitor the evolution of the morphologies and the NIR plasmon absorbance (Figures S7 and S8). An increase in the amount of Pd precursor yielded a thicker shell and a concomitant red-shift of the NIR plasmon absorbance. Also, increasing the reaction temperature to 50 or $80{ }^{\circ} \mathrm{C}$ facilitated the Pd incorporation and led to complete fading of the NIR absorbance after reaction for $4 \mathrm{~h}$ (Figure S8f). Unlike the recent reported reaction of covellite $\mathrm{NCs}$ with $\mathrm{Pt}^{2+}$ ions at $130{ }^{\circ} \mathrm{C}$, which generated hybrid $\mathrm{Cu}_{1.1} \mathrm{~S}-\mathrm{Pt} \mathrm{NCs},{ }^{47}$ and the reaction with $\mathrm{Pd}^{2+}$ at $150{ }^{\circ} \mathrm{C}$, which produced Janus-like heterostructure, ${ }^{43}$ in our case the reaction of $\mathrm{CuS}$ with $\mathrm{Pd}^{2+}$, even at temperatures of $\leq 80{ }^{\circ} \mathrm{C}$, led instead to the formation of amorphous-like ternary $\mathrm{CuPd}_{x} \mathrm{~S}$ nanoplates (with an overall shape and size almost the same as those of the initial CuS NCs) as well as to the side nucleation of smaller metallic Pd NCs that also contained a minor fraction of $\mathrm{S}$ and $\mathrm{Cu}$ (Figure $\mathrm{S} 8 \mathrm{~b}-\mathrm{e}$ ).

According to our density functional theory calculations (see the Supporting Information for the details), the insertion of one $\mathrm{Pd}$ atom per unit cell between the $\mathrm{S}-\mathrm{S}$ layer is much more energetically favorable than other options, for example, the replacement of $\mathrm{Cu}$ with $\mathrm{Pd}$ (see Figure S9 and Table S2 for a complete list of all the possible modes of insertion of $\mathrm{Pd}$ atoms that were tested). Figure S10 shows the relaxed unit cells of pure $\mathrm{CuS}$ and Pd-intercalated NCs $\left(\mathrm{CuSPd}_{0.167} @ 1\right)$. The localization of $\mathrm{Pd}$ between the $\mathrm{S}-\mathrm{S}$ layers induces significant cell expansion (see Table S3 for details). Concomitantly, the $\mathrm{S}-\mathrm{S}$ bonds break, and both $\mathrm{Cu}-\mathrm{S}-\mathrm{Cu}$ and $\mathrm{S}-\mathrm{Cu}-\mathrm{S}$ angles change. We further modeled a $2 \times 1$ supercell, into which four $\mathrm{Pd}$ atoms were inserted (i.e., with a final composition of $\mathrm{Cu}_{12} \mathrm{~S}_{12} \mathrm{Pd}_{4}$ ) at three different locations in the supercell (Figure S11). The comparison of the formation energies at the different sites further confirmed that insertion of Pd between S-S layers is more energetically favorable than elsewhere (see also Table S6). Assuming that any site on the surface of the parent $\mathrm{CuS}$ $\mathrm{NCs}$ is a possible entry point for $\mathrm{Pd}^{2+}$ ions, the formation of core-shell architectures indicates that such ions cannot diffuse to regions that are much farther from their entry point, and that the diffusion proceeds gradually from the surface toward the center of the NCs as the reaction progresses. The limited mobility of $\mathrm{Pd}^{2+}$ ions is probably a consequence of the fact that $\mathrm{Pd}^{2+}$ has a completely different coordination geometry with the sulfur anions compared to that with the $\mathrm{Cu}^{+}$ions, and additionally, it tends to form strong bonds with the sulfur anions, to an extent that further diffusion of $\mathrm{Pd}^{2+}$ ions through the regions affected by this change is limited. This could explain the formation of $\mathrm{CuS} @ \mathrm{CuPd}_{x} \mathrm{~S}$ core-shell heterostructure with a shell thickness that depends on the reaction time. Overall, the reaction of $\mathrm{CuS} \mathrm{NCs}$ with $\mathrm{Pd}^{2+}$ ions is different from our previously reported cases of reaction with either $\mathrm{Cu}^{+}, \mathrm{Cd}^{2+}$, or $\mathrm{Hg}^{2+}$ ions, ${ }^{40,42}$ as in none of those cases were core-shell structures or progressive amorphization of the NC lattice seen; instead, crystalline domains were formed. This can be explained by hypothesizing a diffusion of $\mathrm{Cu}^{+}, \mathrm{Cd}^{2+}$, and $\mathrm{Hg}^{2+}$ ions in the covellite structure faster than that of $\mathrm{Pd}^{2+}$.

We have characterized the tunable optical spectra of the various $\mathrm{CuS} @ \mathrm{CuPd}_{x} \mathrm{~S}$ core-shell NC samples [prepared by tailoring either the reaction time or the precursor $\mathrm{Pd}: \mathrm{Cu}$ molar 
ratios (see Figures S2i and S7f)]. The formation of a very thin amorphous layer already led to a significant red-shift and damping of the NIR plasmon absorbance, which was more marked in NC samples with thicker shells (Figure 3a). Notably,

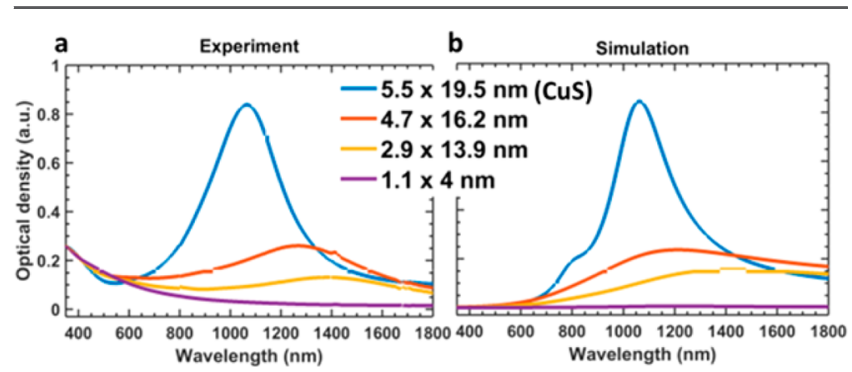

Figure 3. (a) Experimental and (b) simulated optical spectra for four representative core-shell structures with increasing shell thickness from blue (pure covellite) to orange to yellow to purple. The core sizes are given in the legend for the height and the diameter $(h \times d)$.

the shell formation resulted in a significant broadening of the NIR resonance. While in previous works the surface of covellite NCs was modified by ligand exchange to tune their LSPRs, ${ }^{39}$ here the optical response was well modulated by a transformation of the outer layers of the NCs into an amorphous shell. To further elaborate on these observations, we performed simulations (Figure $3 b$ ) to describe the optical properties of the typical core-shell NCs. We implemented a core-shell approach within the framework of the Mie-Gans theory describing oblate particles (see the Supporting Information for details). ${ }^{48}$ The core dielectric function of $\mathrm{CuS}$ was obtained by fitting the extinction spectrum of the parent $\mathrm{CuS}$ nanodisk sample $(d=19.5 \mathrm{~nm}$, and $h=5.5 \mathrm{~nm})$ with the Drude model and by extracting the Drude parameters (see Figure S13). The estimated high-frequency dielectric constant $\left(\varepsilon_{\infty}=8.4\right)$, the plasmon frequency $\left(\omega_{\mathrm{p}}=5.3 \mathrm{eV}\right)$, and the damping constant $(\gamma$ $=0.3 \mathrm{eV})$ are in close agreement with previous works on covellite CuS. ${ }^{9,13}$ The spectrum has a contribution by two overlapping resonances, the longitudinal LSPR, found around $1060 \mathrm{~nm}$ and the less intense transverse LSPR appearing as a slight shoulder to the blue of this resonance, similar to the results found by Xie et al. ${ }^{9}$ We simulated our structure with varying shell thicknesses by choosing a constant refractive index of the amorphous shell. This is a reasonable assumption, as we do not expect a large variation of the refractive index in the investigated wavelength range in the NIR by an amorphous compound. The core and shell dimensions used for the optical simulation were extracted from HRTEM measurements and are listed in Table S8. As it is well-known, the addition of a shell layer with a different refractive index to the core leads to a shift of the LSPR, which has been widely evidenced in nanosized core-shell heterostructures. ${ }^{49-53}$ Indeed, we implemented various different representative values for the refractive index of the shell (between 1.6 and 2.2), illustrating that a further redshift is obtained by increasing the refractive index (Figure S14). From these calculations, we can conclude that the exact value plays a minor role versus the effect of the layer thickness. ${ }^{54}$

Notably, by just taking into account the formation of a shell layer, we were not able to capture the broadening of the LSPR as observed by us experimentally. Indeed, to get a better agreement with the experiment, we also had to vary the Drude damping parameter. An increase in carrier damping generally leads to LSPR broadening and can have several reasons. An important one is the additional surface scattering due to the minimization of the nanostructured dimensions. In our case in particular, the height of the oblate structure is reaching values at which surface scattering is playing a more important role ${ }^{55,56}$ and was observed previously in CuS nanodisks. 'Simulations in which we took into account the anisotropic variation of the damping term along the height of the oblate nanostructure showed an only minor influence by this parameter, as it is mostly affecting the transverse mode, which is weaker and mostly overlapped by the much stronger longitudinal resonance. This is valid for both cases, with and without the formation of a shell (see Figure S15). Indeed, the only reasonable way to reproduce the optical spectra of our NCs was by varying the damping term in all directions of the oblate nanostructure. The results are given in Figure $3 \mathrm{~b}$ and show reasonable overlap between experiment and simulation. The discrepancy observed might be due to a heterogeneous size distribution and a refractive index (which in our case has been fixed to 1.7) slightly different from that chosen by us. The increase in the damping term in all three directions excludes the effect of additional surface scattering. We therefore believe that this additional scattering is occurring in the core of the $\mathrm{CuS}$ nanostructure. This might be due to the incorporation of extra $\mathrm{Pd}$ within the $\mathrm{CuS}$ core, acting as additional scattering centers or adding to carrier localization. ${ }^{10}$

Interestingly, the addition of the amorphous layer not only tuned but also stabilized the NIR plasmon absorbance of the resulting core-shell nanostructure, by making it less sensitive and thus protecting it from the external environment, compared to the starting covellite NCs. This was proven by exposing these NCs to typical redox environments (see Figure 4, Figure S16, and Figure S17). For instance, even after exposure to air for 31 days, little change in the NIR plasmon absorbance was observed on the core-shell nanostructures with an amorphous shell thicker than $2.8 \mathrm{~nm}$ [i.e., with a core size of $2.9 \mathrm{~nm} \times 13.9 \mathrm{~nm}$ (see Figure 4a, Figure S16b,c, and Tables S8 and S9 for details)]. To further investigate the
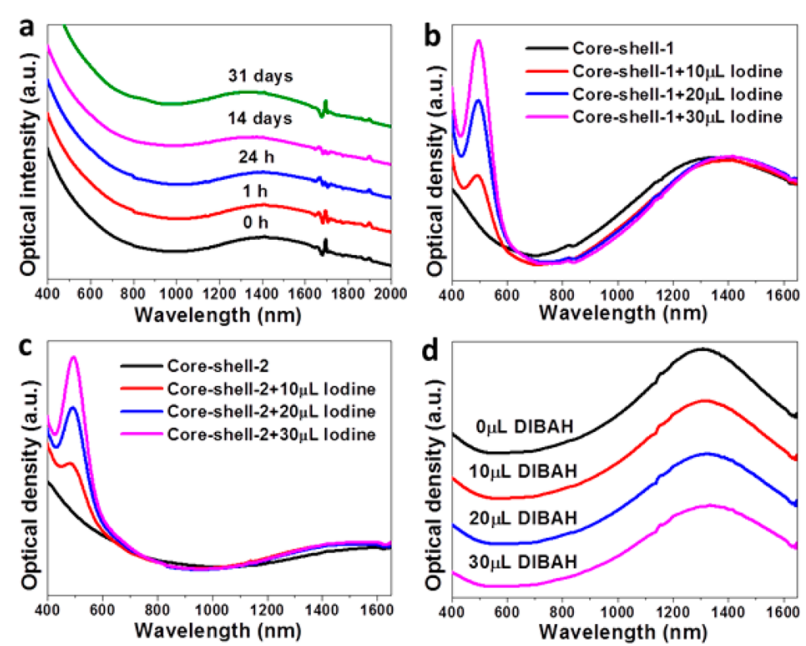

Figure 4. (a) Evolution of optical spectra of the $\mathrm{CuS} @ \mathrm{CuPd}_{x} \mathrm{~S}$ coreshell nanostructure over time upon oxidation by exposure to air. (b and c) Evolution of the optical spectra of the CuS@ $\mathrm{CuPd}_{x} \mathrm{~S}$ coreshell nanostructure over the amounts of $\mathrm{I}_{2}$ added. The shell of the sample in panel $c$ is thicker than that in panel b. (d) Evolution of the optical spectra of $\mathrm{CuS} @ \mathrm{CuPd}_{x} \mathrm{~S}$ core-shell nanostructure over the amounts of DIBAH added. 
stability of NIR plasmonic properties, we performed a test of oxidation reactions using $\mathrm{I}_{2}$ and reduction reactions using DIBAH (both reagents are commonly used to tune the NIR plasmon absorbance of $\mathrm{Cu}_{2-x} \mathrm{E} \mathrm{NCs}{ }^{7}$ ). Only minor shifts were observed on the NIR plasmon properties of the core-shell NCs in these tests (Figure $4 b-d$ ), with samples having thicker shells undergoing less pronounced shifts. The absorption peak around $495 \mathrm{~nm}$ in panels $\mathrm{b}$ and $\mathrm{c}$ of Figure 4 is ascribed to the absorbance of $\mathrm{I}_{2}$ dissolved in toluene (see Figure S17d). It is also noteworthy that the core-shell NCs could preserve their overall morphologies, as well (Figures S18 and S19).

For comparison, we also explored the optical stability of $\mathrm{CuS}$ NCs upon redox reactions by exposure of the as-synthesized $\mathrm{CuS}$ NCs to $\mathrm{I}_{2}$ and DIBAH (see the details in the SI). Although no noticeable change of phase and optical spectra was observed upon mixing of CuS NCs by DIBAH (Figures S20a and S21 of the SI), the broadening and red shift of the NIR plasmonic resonance as well as the slight etching of the CuS NCs in the presence of $\mathrm{I}_{2}$ could not be ignored (see Figures S20b and S22 of the SI). These observations indicate that the as-synthesized covellite NCs were sensitive to the oxidation environment in the presence of $\mathrm{I}_{2}$, while both the NIR plasmon resonances and the morphological properties could be retained when an amorphous $\mathrm{CuPd}_{x} \mathrm{~S}$ shell was present.

\section{CONCLUSION}

We have demonstrated that the synthesis of core-shell heterostructures by reaction of the as-synthesized covellite $\mathrm{CuS}$ nanoplates with $\mathrm{Pd}^{2+}$ cations is a valid tool for tuning and stabilizing the NIR LSPRs of the initial NCs. Pd incorporation, in the presence of an electron donor (i.e., AA), most likely starts by breaking the $S-S$ layers and overall amorphizes the covellite structure. Importantly, the resulting core-shell NCs with a fixed shell thickness preserve their morphology and the NIR plasmon properties by exposure to $\mathrm{I}_{2}$. Our approach demonstrates the fabrication of a prototype core-shell nanostructure with a stabilized NIR LSPR.

\section{ASSOCIATED CONTENT}

\section{S Supporting Information}

The Supporting Information is available free of charge on the ACS Publications website at DOI: 10.1021/acs.chemmater.6b05184.

Additional TEM/HRTEM images, XRD patterns, optical spectra, size distribution histograms, Raman and XPS spectra, elemental analyses, simulation of plasmon absorbance, and calculation based on density functional theory (PDF)

\section{AUTHOR INFORMATION}

\section{Corresponding Authors}

*E-mail: xiey@whut.edu.cn.

*E-mail: liberato.manna@iit.it.

\section{ORCID ${ }^{\circ}$}

Yi Xie: 0000-0002-8075-9214

Liberato Manna: 0000-0003-4386-7985

\section{Notes}

The authors declare no competing financial interest.

\section{ACKNOWLEDGMENTS}

This work was supported by European Union's Seventh Framework Programme FP7/2007-2013 under Grant Agreements 614897 (ERC Grant TRANS-NANO) and the Fundamental Research Funds for the Central Universities (Wuhan University of Technology, WUT) (Grant 2016IVA095). I.K. acknowledges financial support from Global Fellowship MOPTOPus (Marie Curie Actions) of the European Union's Horizon 2020 under Grant Agreement 705444.

\section{REFERENCES}

(1) Hsu, S.-C.; Chuang, Y.-C.; Sneed, B. T.; Cullen, D. A.; Chiu, T.W.; Kuo, C.-H. Turning the Halide Switch in the Synthesis of $\mathrm{Au}-\mathrm{Pd}$ Alloy and Core-Shell Nanoicosahedra with Terraced Shells: Performance in Electrochemical and Plasmon-Enhanced Catalysis. Nano Lett. 2016, 16, 5514-5520.

(2) Chen, J.; Saeki, F.; Wiley, B. J.; Cang, H.; Cobb, M. J.; Li, Z.-Y.; $\mathrm{Au}$, L.; Zhang, H.; Kimmey, M. B.; Li; Xia, Y. Gold Nanocages: Bioconjugation and Their Potential Use as Optical Imaging Contrast Agents. Nano Lett. 2005, 5, 473-477.

(3) Brus, L. Noble Metal Nanocrystals: Plasmon Electron Transfer Photochemistry and Single-Molecule Raman Spectroscopy. Acc. Chem. Res. 2008, 41, 1742-1749.

(4) Ghosh, S. K.; Pal, T. Interparticle Coupling Effect on the Surface Plasmon Resonance of Gold Nanoparticles: From Theory to Applications. Chem. Rev. 2007, 107, 4797-4862.

(5) Luther, J. M.; Jain, P. K.; Ewers, T.; Alivisatos, A. P. Localized Surface Plasmon Resonances Arising from Free Carriers in Doped Quantum Dots. Nat. Mater. 2011, 10, 361-366.

(6) Hsu, S.-W.; On, K.; Tao, A. R. Localized Surface Plasmon Resonances of Anisotropic Semiconductor Nanocrystals. J. Am. Chem. Soc. 2011, 133, 19072-19075.

(7) Kriegel, I.; Jiang, C.; Rodríguez-Fernández, J.; Schaller, R. D.; Talapin, D. V.; da Como, E.; Feldmann, J. Tuning the Excitonic and Plasmonic Properties of Copper Chalcogenide Nanocrystals. J. Am. Chem. Soc. 2012, 134, 1583-1590.

(8) Liu, X.; Wang, X.; Zhou, B.; Law, W.-C.; Cartwright, A. N.; Swihart, M. T. Size-Controlled Synthesis of $\mathrm{Cu}_{2-\mathrm{x}} \mathrm{E}(\mathrm{E}=\mathrm{S}, \mathrm{Se})$ Nanocrystals with Strong Tunable Near-Infrared Localized Surface Plasmon Resonance and High Conductivity in Thin Films. Adv. Funct. Mater. 2013, 23, 1256-1264.

(9) Xie, Y.; Carbone, L.; Nobile, C.; Grillo, V.; D’Agostino, S.; Della Sala, F.; Giannini, C.; Altamura, D.; Oelsner, C.; Kryschi, C.; Cozzoli, P. D. Metallic-like Stoichiometric Copper Sulfide Nanocrystals: Phaseand Shape-Selective Synthesis, Near-Infrared Surface Plasmon Resonance Properties, and Their Modeling. ACS Nano 2013, 7, $7352-7369$.

(10) Kriegel, I.; Rodríguez-Fernández, J.; Wisnet, A.; Zhang, H.; Waurisch, C.; Eychmüller, A.; Dubavik, A.; Govorov, A. O.; Feldmann, J. Shedding Light on Vacancy-Doped Copper Chalcogenides: ShapeControlled Synthesis, Optical Properties, and Modeling of Copper Telluride Nanocrystals with Near-Infrared Plasmon Resonances. ACS Nano 2013, 7, 4367-4377.

(11) Faucheaux, J. A.; Stanton, A. L. D.; Jain, P. K. Plasmon Resonances of Semiconductor Nanocrystals: Physical Principles and New Opportunities. J. Phys. Chem. Lett. 2014, 5, 976-985.

(12) Wang, X.; Swihart, M. T. Controlling the Size, Shape, Phase, Band Gap, and Localized Surface Plasmon Resonance of $\mathrm{Cu}_{2-\mathrm{x}} \mathrm{S}$ and $\mathrm{Cu}_{\mathrm{x}} \mathrm{In}_{\mathrm{y}} \mathrm{S}$ Nanocrystals. Chem. Mater. 2015, 27, 1786-1791.

(13) Liu, M.; Xue, X.; Ghosh, C.; Liu, X.; Liu, Y.; Furlani, E. P.; Swihart, M. T.; Prasad, P. N. Room-Temperature Synthesis of Covellite Nanoplatelets with Broadly Tunable Localized Surface Plasmon Resonance. Chem. Mater. 2015, 27, 2584-2590.

(14) Liu, X.; Swihart, M. T. Heavily-Doped Colloidal Semiconductor and Metal Oxide Nanocrystals: an Emerging New Class of Plasmonic Nanomaterials. Chem. Soc. Rev. 2014, 43, 3908-3920. 
(15) Zhao, Y.; Pan, H.; Lou, Y.; Qiu, X.; Zhu, J.; Burda, C. Plasmonic $\mathrm{Cu}_{2-\mathrm{x}} \mathrm{S}$ Nanocrystals: Optical and Structural Properties of CopperDeficient Copper (I) Sulfides. J. Am. Chem. Soc. 2009, 131, 42534261.

(16) Niezgoda, J. S.; Harrison, M. A.; McBride, J. R.; Rosenthal, S. J. Novel Synthesis of Chalcopyrite $\mathrm{Cu}_{\mathrm{x}} \mathrm{In}_{\mathrm{y}} \mathrm{S}_{2}$ Quantum Dots with Tunable Localized Surface Plasmon Resonances. Chem. Mater. 2012, 24, 3294-3298.

(17) Balitskii, O. A.; Sytnyk, M.; Stangl, J.; Primetzhofer, D.; Groiss, H.; Heiss, W. Tuning the Localized Surface Plasmon Resonance in $\mathrm{Cu}_{2-\mathrm{x}} \mathrm{Se}$ Nanocrystals by Postsynthetic Ligand Exchange. ACS Appl. Mater. Interfaces 2014, 6, 17770-17775.

(18) Lie, S. Q.; Wang, D. M.; Gao, M. X.; Huang, C. Z. Controllable Copper Deficiency in $\mathrm{Cu}_{2-\mathrm{x}} \mathrm{Se}$ Nanocrystals with Tunable Localized Surface Plasmon Resonance and Enhanced Chemiluminescence. Nanoscale 2014, 6, 10289-10296.

(19) Dorfs, D.; Härtling, T.; Miszta, K.; Bigall, N. C.; Kim, M. R.; Genovese, A.; Falqui, A.; Povia, M.; Manna, L. Reversible Tunability of the Near-Infrared Valence Band Plasmon Resonance in $\mathrm{Cu}_{2-\mathrm{x}} \mathrm{Se}$ Nanocrystals. J. Am. Chem. Soc. 2011, 133, 11175-11180.

(20) Alam, R.; Labine, M.; Karwacki, C. J.; Kamat, P. V. Modulation of $\mathrm{Cu}_{2-\mathrm{x}} \mathrm{S}$ Nanocrystal Plasmon Resonance through Reversible Photoinduced Electron Transfer. ACS Nano 2016, 10, 2880-2886.

(21) Ghosh, S. K.; Nath, S.; Kundu, S.; Esumi, K.; Pal, T. Solvent and Ligand Effects on the Localized Surface Plasmon Resonance (LSPR) of Gold Colloids. J. Phys. Chem. B 2004, 108, 13963-13971.

(22) Hsu, S.-W.; Ngo, C.; Bryks, W.; Tao, A. R. Shape Focusing During the Anisotropic Growth of CuS Triangular Nanoprisms. Chem. Mater. 2015, 27, 4957-4963.

(23) Liu, L.; Zhong, H.; Bai, Z.; Zhang, T.; Fu, W.; Shi, L.; Xie, H.; Deng, L.; Zou, B. Controllable Transformation from Rhombohedral $\mathrm{Cu}_{1.8} \mathrm{~S}$ Nanocrystals to Hexagonal CuS Clusters: Phase- and Composition-Dependent Plasmonic Properties. Chem. Mater. 2013, $25,4828-4834$.

(24) Zhou, M.; Zhang, R.; Huang, M.; Lu, W.; Song, S.; Melancon, M. P.; Tian, M.; Liang, D.; Li, C. A Chelator-Free Multifunctional $\left[{ }^{64} \mathrm{Cu}\right] \mathrm{CuS}$ Nanoparticle Platform for Simultaneous Micro-PET/CT Imaging and Photothermal Ablation Therapy. J. Am. Chem. Soc. 2010, 132, 15351-15358.

(25) Li, Y.; Lu, W.; Huang, Q.; Li, C.; Chen, W. Copper Sulfide Nanoparticles for Photothermal Ablation of Tumor Cells. Nanomedicine 2010, 5, 1161-1171.

(26) Hessel, C. M.; Pattani, V. P.; Rasch, M.; Panthani, M. G.; Koo, B.; Tunnell, J. W.; Korgel, B. A. Copper Selenide Nanocrystals for Photothermal Therapy. Nano Lett. 2011, 11, 2560-2566.

(27) Tian, Q.; Tang, M.; Sun, Y.; Zou, R.; Chen, Z.; Zhu, M.; Yang, S.; Wang, J.; Wang, J.; Hu, J. Hydrophilic Flower-Like CuS Superstructures as an Efficient $980 \mathrm{~nm}$ Laser-Driven Photothermal Agent for Ablation of Cancer Cells. Adv. Mater. 2011, 23, 3542-3547.

(28) Zhao, Y.; Burda, C. Development of Plasmonic Semiconductor Nanomaterials with Copper Chalcogenides for a Future with Sustainable Energy Materials. Energy Environ. Sci. 2012, 5, 5564-5576.

(29) Li, W.; Zamani, R.; Rivera Gil, P.; Pelaz, B.; Ibáñez, M.; Cadavid, D.; Shavel, A.; Alvarez-Puebla, R. A.; Parak, W. J.; Arbiol, J.; Cabot, A. CuTe Nanocrystals: Shape and Size Control, Plasmonic Properties, and Use as SERS Probes and Photothermal Agents. J. Am. Chem. Soc. 2013, 135, 7098-7101.

(30) Li, B.; Wang, Q.; Zou, R.; Liu, X.; Xu, K.; Li, W.; Hu, J. $\mathrm{Cu}_{7.2} \mathrm{~S}_{4}$ Nanocrystals: a Novel Photothermal Agent with a 56.7\% Photothermal Conversion Efficiency for Photothermal Therapy of Cancer Cells. Nanoscale 2014, 6, 3274-3282.

(31) Wang, S.; Riedinger, A.; Li, H.; Fu, C.; Liu, H.; Li, L.; Liu, T.; Tan, L.; Barthel, M. J.; Pugliese, G.; De Donato, F.; Scotto D’Abbusco, M.; Meng, X.; Manna, L.; Meng, H.; Pellegrino, T. Plasmonic Copper Sulfide Nanocrystals Exhibiting Near-Infrared Photothermal and Photodynamic Therapeutic Effects. ACS Nano 2015, 9, 1788-1800.

(32) Ortiz de Solorzano, I.; Prieto, M.; Mendoza, G.; Alejo, T.; Irusta, S.; Sebastian, V.; Arruebo, M. Microfluidic Synthesis and Biological
Evaluation of Photothermal Biodegradable Copper Sulfide Nanoparticles. ACS Appl. Mater. Interfaces 2016, 8, 21545-21554.

(33) Liu, Z.; Liu, X.; Du, Y.; Ren, J.; Qu, X. Using Plasmonic Copper Sulfide Nanocrystals as Smart Light-Driven Sterilants. ACS Nano 2015, 9, 10335-10346.

(34) Wang, Z.; Huang, P.; Jacobson, O.; Wang, Z.; Liu, Y.; Lin, L.; Lin, J.; Lu, N.; Zhang, H.; Tian, R.; Niu, G.; Liu, G.; Chen, X. Biomineralization-Inspired Synthesis of Copper Sulfide-Ferritin Nanocages as Cancer Theranostics. ACS Nano 2016, 10, 3453-3460.

(35) Zhou, M.; Li, J.; Liang, S.; Sood, A. K.; Liang, D.; Li, C. CuS Nanodots with Ultrahigh Efficient Renal Clearance for Positron Emission Tomography Imaging and Image-Guided Photothermal Therapy. ACS Nano 2015, 9, 7085-7096.

(36) Liu, L.; Zhou, B.; Deng, L.; Fu, W.; Zhang, J.; Wu, M.; Zhang, W.; Zou, B.; Zhong, H. Thermal Annealing Effects of Plasmonic $\mathrm{Cu}_{1.8} \mathrm{~S}$ Nanocrystal Films and Their Photovoltaic Properties. J. Phys. Chem. C 2014, 118, 26964-26972.

(37) Jain, P. K.; Manthiram, K.; Engel, J. H.; White, S. L.; Faucheaux, J. A.; Alivisatos, A. P. Doped Nanocrystals as Plasmonic Probes of Redox Chemistry. Angew. Chem., Int. Ed. 2013, 52, 13671-13675.

(38) Georgieva, Z. N.; Tomat, M. A.; Kim, C.; Plass, K. E. Stabilization of Plasmon Resonance in $\mathrm{Cu}_{2-\mathrm{x}} \mathrm{S}$ Semiconductor Nanoparticles. Chem. Commun. 2016, 52, 9082-9085.

(39) Wei, T.; Liu, Y.; Dong, W.; Zhang, Y.; Huang, C.; Sun, Y.; Chen, X.; Dai, N. Surface-Dependent Localized Surface Plasmon Resonances in CuS Nanodisks. ACS Appl. Mater. Interfaces 2013, 5, 10473-10477.

(40) Xie, Y.; Bertoni, G.; Riedinger, A.; Sathya, A.; Prato, M.; Marras, S.; Tu, R.; Pellegrino, T.; Manna, L. Nanoscale Transformations in Covellite $(\mathrm{CuS})$ Nanocrystals in the Presence of Divalent Metal Cations in a Mild Reducing Environment. Chem. Mater. 2015, 27, $7531-7537$.

(41) Fraser, H. J. Microchemistry of the Precious-Metal Elements. Am. Mineral. 1937, 22, 1016-1034.

(42) Xie, Y.; Riedinger, A.; Prato, M.; Casu, A.; Genovese, A.; Guardia, P.; Sottini, S.; Sangregorio, C.; Miszta, K.; Ghosh, S.; Pellegrino, T.; Manna, L. Copper Sulfide Nanocrystals with Tunable Composition by Reduction of Covellite Nanocrystals with $\mathrm{Cu}^{+}$Ions. J. Am. Chem. Soc. 2013, 135, 17630-17637.

(43) Wang, Y.; Chen, Z.; Shen, R.; Cao, X.; Chen, Y.; Chen, C.; Wang, D.; Peng, Q.; Li, Y. Pd-Dispersed CuS Hetero-Nanoplates for Selective Hydrogenation of Phenylacetylene. Nano Res. 2016, 9, 1209-1219.

(44) Ishii, M.; Shibata, K.; Nozaki, H. Anion Distributions and Phase Transitions in $\mathrm{CuS}_{1-\mathrm{x}} \mathrm{Se}_{\mathrm{x}}(\mathrm{x}=0-1)$ Studied by Raman Spectroscopy. J. Solid State Chem. 1993, 105, 504-511.

(45) Pikl, R.; Waal, D. D.; Merkle, R. K. W.; Verryn, S. M. C. Raman Spectroscopic Identification of Synthetic "Braggite" (Pt, Pd, Ni)S Samples in Comparison with Synthetic "Cooperite". Appl. Spectrosc. 1999, 53, 927-930.

(46) Merkle, R. K. W.; Pikl, R.; Verryn, S. M. C.; Waal, D. d. Raman Spectra of Synthetic 'Braggite', (Pd,Pt,Ni)S. Mineral. Mag. 1999, 63, 363-367.

(47) Wolf, A.; Hinrichs, D.; Sann, J.; Miethe, J. F.; Bigall, N. C.; Dorfs, D. Growth of $\mathrm{Cu}_{2-\mathrm{x}} \mathrm{Se}-\mathrm{CuPt}$ and $\mathrm{Cu}_{1.1} \mathrm{~S}$-Pt Hybrid Nanoparticles. J. Phys. Chem. C 2016, 120, 21925-21931.

(48) Caldwell, A. H.; Ha, D.-H.; Ding, X.; Robinson, R. D. Analytical Modeling of Localized Surface Plasmon Resonance in Heterostructure Copper Sulfide Nanocrystals. J. Chem. Phys. 2014, 141, 164125.

(49) Chen, H.; Shao, L.; Li, Q.; Wang, J. Gold Nanorods and Their Plasmonic Properties. Chem. Soc. Rev. 2013, 42, 2679-2724.

(50) Li, B.; Gu, T.; Ming, T.; Wang, J.; Wang, P.; Wang, J.; Yu, J. C. (Gold Core)@(Ceria Shell) Nanostructures for Plasmon-Enhanced Catalytic Reactions under Visible Light. ACS Nano 2014, 8, 81528162.

(51) Muhammed, M. A. H.; Döblinger, M.; Rodríguez-Fernández, J. Switching Plasmons: Gold Nanorod-Copper Chalcogenide CoreShell Nanoparticle Clusters with Selectable Metal/Semiconductor NIR Plasmon Resonances. J. Am. Chem. Soc. 2015, 137, 11666-11677. 
(52) Mayer, K. M.; Hafner, J. H. Localized Surface Plasmon Resonance Sensors. Chem. Rev. 2011, 111, 3828-3857.

(53) Ha, D.-H.; Caldwell, A. H.; Ward, M. J.; Honrao, S.; Mathew, K.; Hovden, R.; Koker, M. K. A.; Muller, D. A.; Hennig, R. G.; Robinson, R. D. Solid-Solid Phase Transformations Induced through Cation Exchange and Strain in 2D Heterostructured Copper Sulfide Nanocrystals. Nano Lett. 2014, 14, 7090-7099.

(54) Li, J.; Cushing, S. K.; Bright, J.; Meng, F.; Senty, T. R.; Zheng, P.; Bristow, A. D.; Wu, N. Ag@ $\mathrm{Cu}_{2} \mathrm{O}$ Core-Shell Nanoparticles as Visible-Light Plasmonic Photocatalysts. ACS Catal. 2013, 3, 47-51.

(55) Kraus, W. A.; Schatz, G. C. Plasmon Resonance Broadening in Small Metal Particles. J. Chem. Phys. 1983, 79, 6130-6139.

(56) Hu, M.; Novo, C.; Funston, A.; Wang, H.; Staleva, H.; Zou, S.; Mulvaney, P.; Xia, Y.; Hartland, G. V. Dark-Field Microscopy Studies of Single Metal Nanoparticles: Understanding the Factors that Influence the Linewidth of the Localized Surface Plasmon Resonance. J. Mater. Chem. 2008, 18, 1949-1960. 